\title{
Effects of a periodized functional strength training program (FST) on Functional Movement Screen (FMS) in physical education students
}

Michał Sawczyn ${ }^{\mathrm{ABCDE}}$

University of Physical Education and Sport in Gdansk, Poland

Authors' Contribution: A - Study design; B - Data collection; C - Statistical analysis; D - Manuscript Preparation; E- Funds Collection

\section{Abstract}

Purpose: $\quad$ To examine the effects of periodized functional strength training (FST) on FMS scores of sport university students with higher risk of injury.

Material: $\quad$ Thirty three participants (age $21.6 \pm 1.3$ years, height $177.8 \pm 6.9 \mathrm{~m}$, mass $80.4 \pm 7.7 \mathrm{~kg}$ ) with Functional Movement Screen (FMS), total score $\leq 14$, were selected from eighty two volunteered students of University of Physical Education and Sport in Gdansk and randomly assigned to experimental $(n=16)$ and control group $(n=17)$. The FMS test was conducted one week before and one week after the 12 week training intervention. The experimental group participated in FST program through 12 weeks. The control group did not engage in any additional physical activity than planned in their course of study. The collected data were analysed using Statistica $13.3 \mathrm{pl}$ (StatSoft Inc). Wilcoxon signed rank test was used to establish the statistical significance of the difference between FMS total scores within each group and Mann Whitney $U$ test between groups before and after the 12 week training intervention.

Results: $\quad 45 \%$ of volunteers in the first FMS testing showed total scores $\leq 14$. The experimental group that participated in functional strength training (FST) program changed significantly FMS total scores after 12 weeks $(p<0.05)$. There were also significant differences in FMS total score between groups after the experiment $(p<0.05)$.

Conclusions: There is a need for injury prevention programs for students of University of Physical Education and Sport in Gdansk. It is clear from this study that FST is effective in improving FMS total score in students with cut off score $\leq 14$.

Keywords: injury prevention, male students, functional strength training, functional movement screen.

\section{Introduction}

Injury risk can be a major concern while participating in any kinds of physical activities or sports. Especially musculoskeletal injuries are an inherent risk of athletic performance. Noncontact injuries represent approximately $20 \%$ of all injuries incurred during games and $40 \%$ of injuries incurred during practices among collegiate students [1]. To minimize the risk of injuries, an effective way to identify physical dysfunctions exposing to injury and injury prevention program are needed. In order to asses injury risk during various physical activities, several movement oriented tests have been established [2-5]. One of the most popular injury risk assessments is the Functional Movement Screen (FMS).

Over the past years, many studies have investigated the reliability and validity of the FMS [6-8]. The FMS consists of 7 tests: the deep squat, the in-line lunge, the hurdle step, shoulder mobility, active straight leg raises, trunk stability push-up, and the rotary trunk stability assessment $[2,9]$. Each test is scored on a scale of $0-3$ with a maximum value of 21 for the 7 tests. Bonazza et al. [6] in their meta-analysis stated that the FMS had the ability to predict injury risk and determined that athletes who scored $\leq 14$ on the FMS were 2 times more likely to sustain an injury during training. Similar conclusions were stated by another meta-analysis by Bunn et al. [7]; (c) Michał Sawczyn, 2020

doi:10.15561/20755279.2020.0306 individuals who scored $\leq 14$ were $51 \%$ more likely to sustain a musculoskeletal injury. Furthermore, Kiesel et al. [10] reported that subjects who showed an asymmetry were 3 times more likely to become injured even with scores above the injury risk factor of 14 .

A variety of intervention programs have been used to retrain dysfunctional movement patterns and increase FMS scores above 14 points [11-14]. Programs focused on coordination, neuromuscular control showed their effectiveness in increasing FMS scores. Bodden et al. [15] showed a sufficient increase in total FMS scores above 14 in experimental group that used the FMS protocol based on neuromuscular control after 4 weeks. Jafari et al. [16] reported a significant increase in total FMS score in firefighters after 8 weeks NASM (National Academy of Sport Medicine) training protocol based on flexibility and neuromuscular control.

Several studies have examined changes in FMS total score after different modes of resistance training [17-20]. Recently a new type of strength training modality known as functional strength training (FST) emerged among fitness as well as strength and conditioning professionals. FST employs multiple planes of motion, targets multiple muscles in a single exercise and mimics movement patterns seen in everyday life or sport [21, 22]. In contrast, traditional strength training programs incorporate more isolation/machine training and one plane of motion 
exercises. Liao et al. [19] reported significantly greater increases in FMS total scores after FST compared to traditional strength training among 12-13 years old girls. Similar observations were made by Yildiz et al. [18] that showed greater improvements in movement competency after functional strength training in comparison to traditional strength training in young tennis players. Nonetheless only one study analyzed the influence of periodized strength training on FMS total score. CosioLima et al. [20] compared changes in FMS total scores between periodized traditional strength training group and typical military training group of army cadets after 12 weeks. The research showed no statistical meaningful changes in any of the groups.

However, up to date, no previous studies have sought to examine the effectiveness of periodized FST on FMS total score in adults. Therefore the aim of this study was to examine the effects of periodized FST using kettlebells and bodyweight exercises on FMS scores of sport university students with higher risk of injury $(\leq 14$ on the FMS).

\section{Material and methods}

Participants:

Eighty two students of physical education of Gdansk University of Physical Education and Sport (mean age: $21.6 \pm 1.3$ years, mean height: $177.8 \pm 6.9 \mathrm{~cm}$, mean body mass: $80.4 \pm 7.7 \mathrm{~kg}$ ) volunteered for the first part of the study. The inclusion criteria allowing subjects to participate in the second part of the study consisted of: receiving no more than 14 points on FMS total score, not receiving 0 score on any of the FMS tests, being not involved in professional sport training in the previous 2 years, having no recent injury. The subjects that fulfilled the inclusion criteria $(n=33)$, were randomly assigned into an experimental group $(n=16)$ or a control group $(n=17)$.

\section{Procedure:}

The study had two parts. In the first part, the FMS total score profile of 82 subjects that volunteered to participate in the study, was assessed. In the second part of the study, only participants that fulfilled the inclusion criteria took part. The experimental group participated in FST program through 12 weeks. The control group was not engaged in any additional physical activity than planned in their course of study. The FMS total scores were determined after 12 weeks of FST program in experimental as well as in control group. The anthropometric measures were performed only once, one week before the 12 week strength training program for creating the anthropometric profile of all participants.

The FMS is a screening tool comprised of 7 individual tests to assess an individual's overall functional movement capacity. The FMS consists of 7 movement patterns that include an overhead deep squat (DS), a hurdle step (HS), an in-line lunge (ILL), shoulder mobility (SM), active straight leg raise (ASLR), trunk stability push-up (TSPU) and rotary stability (RS). Details of each movement task of the FMS test have been published previously [2]. The scoring system range for each of the 7 screen tests is from
0 to 3 , where 3 indicates appropriate execution of the movement pattern, 2 indicates execution of the movement pattern with some compensatory adjustments, 1 indicates inability to perform the movement pattern and 0 indicates pain during the test. Each task was performed three times, and the best result was used for further analysis. Total score from all 7 tests range from 0 to 21. A total score of $\leq 14$ was operationally defined as a cut-off score to determine poor movement capacity $[6,7]$. The FMS test was conducted by 3 certified instructors. The FMS test was completed by using standard equipment (FMS Test Kit, Functional Movement Systems Inc., Chatham, Virginia, USA). All anthropometric data were collected by a physician specifically trained according to a standardized protocol. Height was recorded to the nearest $0.1 \mathrm{~cm}$ with a standing stadiometer (Seca 217) and body mass was measured to the nearest $0.1 \mathrm{~kg}$ with a highprecision mechanical scale (ADE M318800).

The strength training program was constructed on a traditional linear periodization model, based on developing high-volume and low-intensity training during the first mesocycles of the macrocycle, with progressive increases in training intensity and technical skills with simultaneous decreases in training volumes of the consecutive mesocycles (Table 1) [23]. The training program involved 8 multi joint exercises divided into two training days for 4 exercises per each training day. Each training day consisted of 2 lower body exercises, one upper body exercise and one global exercise. With each mesocycle the technical execution and intensity of each exercise increased by changing body position, increasing range of motion, changing tempo of exercise execution and adding external load. The intensity was monitored and expressed via perceived exertion (RPE) values measuring repetitions in reserve (RIR) [24]. Each workout was conducted under supervision of certified personal trainers.

Statistical analysis:

Statistical analyses were completed in Statistica 13.3 pl (StatSoft Inc). Descriptive statistics (mean and standard deviation) were calculated. Because the assumption of normality and homoscedasticity were violated on the Saphiro-Wilk test, Wilcoxon signed rank test was used to establish the statistical significance of the difference between FMS total scores within each group and Mann Whitney $U$ test between groups before and after the 12 week training intervention. $\mathrm{P}<0.05$ values were accepted statistically significant in all analyzes.

\section{Results}

Figure 1 presents FMS total score distribution among all volunteers before training intervention. Table 2 shows FMS total score distribution among experimental group and control group before and after 12 week training intervention. FMS total scores between pre-test results and post-test results are presented in Table 3. There was a significant difference between FMS total scores before and after the 12 week intervention in the experimental group, $(\mathrm{p}<0.05)$ and no significant changes in the control group $(\mathrm{p}>0.05)$ see Table 3 . There was no difference in 


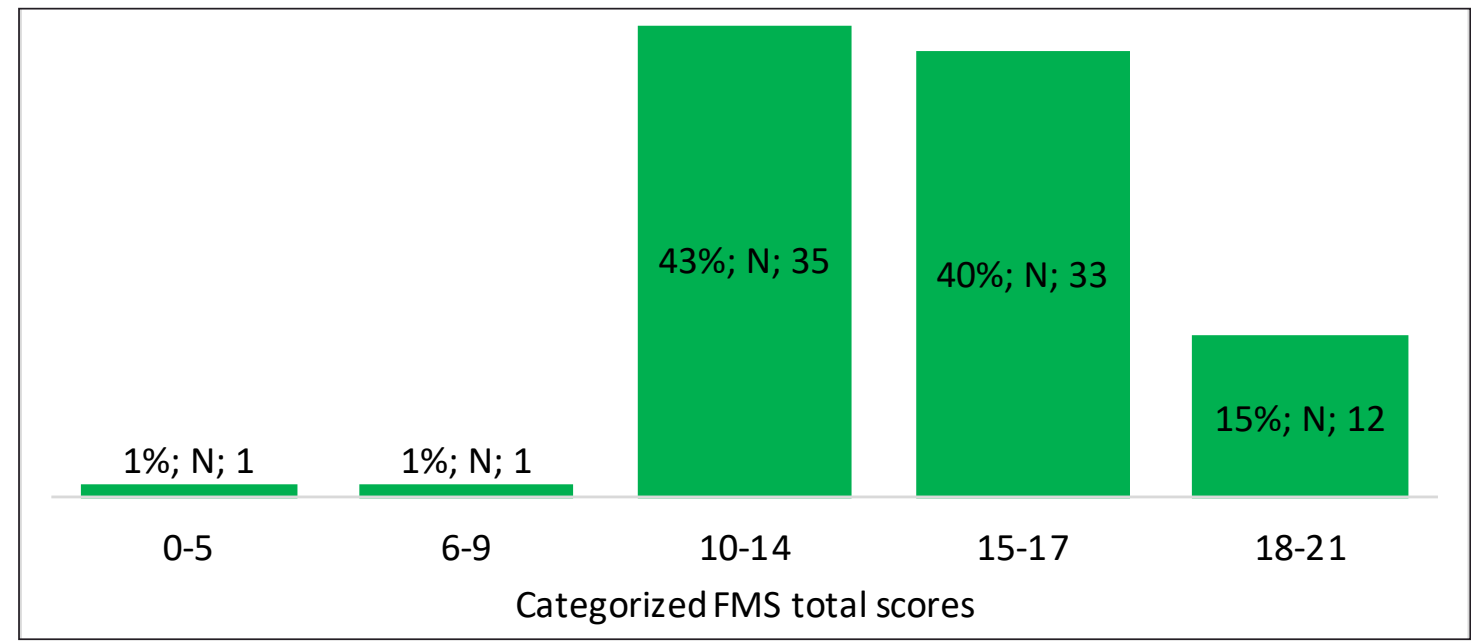

Fig. 1. FMS total score distribution among all volunteers before training intervention

Table 1. 12 week strength training program*

RIR-repetitions in reserve

\begin{tabular}{|c|c|c|c|c|}
\hline $\begin{array}{l}\text { Exercise/movement } \\
\text { pattern }\end{array}$ & Week 1-3 & Week 4-6 & Week 7-9 & Week 10-12 \\
\hline Squat & $\begin{array}{l}\text { Body weight } \\
\text { squat with valgus } \\
\text { correction }\end{array}$ & $\begin{array}{l}\text { Squat with } \\
\text { kettlebell }\end{array}$ & $\begin{array}{l}\text { Kettlebell goblet hold } \\
\text { squat }\end{array}$ & $\begin{array}{l}2 \text { kettlebell front } \\
\text { squat }\end{array}$ \\
\hline Push up & Push up walk out & Push up & $\begin{array}{l}\text { Push up on } \\
\text { suspension trainer }\end{array}$ & $\begin{array}{l}\text { Push up on } \\
\text { suspension trainer- } \\
\text { feet elevated }\end{array}$ \\
\hline Get up & $\begin{array}{l}\text { Get up to press with } \\
\text { kettlebell }\end{array}$ & $\begin{array}{l}\text { Get up high pelvis } \\
\text { to bend with } \\
\text { kettlebell }\end{array}$ & $\begin{array}{l}\text { Get up post to high } \\
\text { pelvis with kettlebell }\end{array}$ & $\begin{array}{l}\text { Get up to half } \\
\text { kneeling with } \\
\text { kettlebell }\end{array}$ \\
\hline Hip bridge & $\begin{array}{l}1 \text { leg isometric hold } \\
\text { hip bridge }\end{array}$ & $\begin{array}{l}2 \text { leg dynamic hip } \\
\text { bridge }\end{array}$ & $\begin{array}{l}2 \text { leg dynamic hip } \\
\text { bridge with shoulders } \\
\text { on a bench }\end{array}$ & $\begin{array}{l}1 \text { leg dynamic hip } \\
\text { bridge with shoulders } \\
\text { on a bench }\end{array}$ \\
\hline \multicolumn{5}{|l|}{ Day 2} \\
\hline $\begin{array}{l}\text { Exercise/movement } \\
\text { pattern }\end{array}$ & Week 1-3 & Week 4-6 & Week 7-9 & Week10-12 \\
\hline Lunge & $\begin{array}{l}\text { Split squat with body } \\
\text { weight }\end{array}$ & $\begin{array}{l}\text { Split squat with } \\
\text { kettlebell-goblet } \\
\text { hold }\end{array}$ & $\begin{array}{l}\text { Forward lunge with } \\
\text { kettlebell-goblet hold }\end{array}$ & $\begin{array}{l}\text { Forward lunge with } \\
2 x k e t t l e b e l l \text { in front } \\
\text { of the chest }\end{array}$ \\
\hline Hip hinge & $\begin{array}{l}\text { Hip hinge with } \\
\text { elastic band }\end{array}$ & $\begin{array}{l}\text { Romanian deadlift } \\
\text { with kettlebell } \\
\text { from a box }\end{array}$ & $\begin{array}{l}\text { Romanian deadlift } \\
\text { with kettlebell from } \\
\text { the ground }\end{array}$ & $\begin{array}{l}\text { Romanian deadlift } \\
\text { with } 2 \text { xkettlebell } \\
\text { from the ground }\end{array}$ \\
\hline Upper body pull & $\begin{array}{l}\text { Half kneeling row } \\
\text { with resistance band }\end{array}$ & $\begin{array}{l}\text { Suspension } \\
\text { trainer row }\end{array}$ & $\begin{array}{l}\text { Suspension trainer } \\
\text { row with one hand }\end{array}$ & $\begin{array}{l}\text { Suspension trainer } \\
\text { row-feet elevated }\end{array}$ \\
\hline Windmill & Bodyweight windmill & $\begin{array}{l}\text { Windmill with } \\
\text { kettlebell }\end{array}$ & $\begin{array}{l}\text { Windmill with } \\
\text { kettlebell }\end{array}$ & $\begin{array}{l}\text { Windmill with } \\
\text { 2xkettlebell }\end{array}$ \\
\hline
\end{tabular}

*Week 1-3: 16-20 rep., RIR 4, tempo 4-2-2 (ex.-iso-con.), 3 set, 60 seconds. rest, 4 session/week (2xday 1, 2xday 2), 10 minutes. Warm-up/40-50 minutes of training/10 minutes of cooling; Week 4-6: 12-15 rep., RIR 3, tempo 3-1-2 (ex.-iso-con.), 3 set, 90 seconds. Rest, 4 session/week (2xday 1, 2xday 2), 10 minutes. Warm-up/40-50 minutes of training/10 minutes of cooling; Week 7-9: 8-10 rep., RIR 2-3, tempo 2-1-2 (ex.-iso-con.), 4 set, 120 seconds. Rest, 2 session/week (day 1, day2), 10 minutes. Warm-up/40-50 minutes of training/10 minutes of cooling; Week 10-12: 5-7 rep., RIR 1-2, tempo 2-1-2 (ex.-iso-con.), 4 set, 180 seconds. Rest, 2 session/week (day 1, day 2), 10 minutes. Warm-up/40-50 minutes of training/10 minutes of cooling. 
Table 2. FMS total score distribution in control and experimental groups pre testing and post testing conditions

\begin{tabular}{llllll}
\hline Testing timeframe & TS & $\begin{array}{l}\text { Control group } \\
\text { (n) }\end{array}$ & $\begin{array}{l}\text { Percent } \\
\text { (\%) }\end{array}$ & $\begin{array}{l}\text { Experimental } \\
\text { group } \\
\text { (n) }\end{array}$ & $\begin{array}{l}\text { Percent } \\
\text { (\%) }\end{array}$ \\
\hline \multirow{3}{*}{ Pre } & 12 & 2 & 11.765 & 1 & 6.25 \\
& 13 & 4 & 23.529 & 3 & 18.75 \\
\hline & 14 & 11 & 64.706 & 12 & 75 \\
Post & 12 & 3 & 17.647 & 0 & 0 \\
& 13 & 5 & 29.412 & 0 & 0 \\
& 14 & 7 & 4.176 & 0 & 6.25 \\
& 15 & 2 & 11.765 & 1 & 37.5 \\
\end{tabular}

NOTE: Pre - tests before training intervention, Post - tests after training intervention, TS - FMS total score.

Table 3. FMS total score changes within groups

\begin{tabular}{lllllll}
\hline Group & $\mathbf{n}$ & $\begin{array}{l}\text { Pre } \\
\text { (mean } \pm \text { SD) }\end{array}$ & $\begin{array}{l}\text { Post } \\
\text { (mean } \pm \text { SD) }\end{array}$ & $\begin{array}{l}\text { MD } \\
\text { (post-pre) }\end{array}$ & $\begin{array}{l}\text { Difference } \\
\text { ratio } \\
\text { (\%) }\end{array}$ & P \\
\hline $\begin{array}{l}\text { Control group } \\
\begin{array}{l}\text { Experimental } \\
\text { group }\end{array}\end{array}$ & 17 & $13.529 \pm 0.717$ & $13.471 \pm 0.943$ & -0.058 & -0.03 & 0.777 \\
\hline
\end{tabular}

NOTE: Pre - tests before training intervention, Post - tests after training intervention, MD - mean difference.

baseline values in the FMS total score between control and experimental group $(\mathrm{MD}=-0.159, \mathrm{p}=0.518)$. However a significant difference was found after pre-test and posttest FMS total scores between groups $(\mathrm{MD}=-3.154$, $\mathrm{p}<0.001)$.

\section{Discussion}

The main purpose of this study was to examine the effectiveness of 12 week, periodized FST program on FMS total scores in physical education students with baseline score $\leq 14$. The FMS total score profile of volunteered students showed that $45 \%$ of them are at higher risk of sustaining an injury. Two meta-analysis confirm that FMS total scores $\leq 14$ are associated with higher injury risk [6, 7]. It might indicate that participants with cut-off score $\leq 14$ have poor movement competency due to limited joint range of motion, stability and movement control [2, 25-28].

The primary finding of this study was the significant time-by-intervention effects on FMS total score. There were significant differences within experimental group before and after training intervention $(p<0.05)$ and between experimental and control group after the intervention $(p<0.05)$. All participants in the experimental group increased their FMS total score above 14. This is the first study to examine the effectiveness of periodized FST on FMS total score in young active adults. The results were consistent with previous intervention studies that examined effectiveness of FST on movement competency in children $[18,19]$. However previous studies did not used a periodized strength training program and participants were adolescents.

In this study a linear periodization was used. Periodized training programs were used firstly only in professional athletic populations, however today it is also widely used with untrained population and amateur athletes. Williams et al. [29] in their meta-analysis showed that periodized strength training programs are more effective in developing strength than non-periodized programs either in athletic and untrained population. Nonetheless, there is little evidence of periodized programs on FMS total score. Only one study by Cosio-Lima et al. [30] examined changes in FMS total score after periodized traditional strength training program. The researchers found no significant changes in FMS total score. Studies that also used traditional strength training demonstrated no meaningful FMS total score changes $[18,19]$. Based on the results of the current research, periodized functional strength training (FST) is able to increase FMS total scores above cut off score $\leq 14$.

Functional strength training is based on developing strength in particular movement patterns in contrast to traditional strength training where emphasis on strengthening muscle groups is placed on. FST has been demonstrated to not only have direct benefits on FMS total scores but also on athletic performance. Number of studies 
have indicated that FST can develop specific athletic performance variables such as counter movement jump, sprint time, agility or maximal strength as affectively as traditional strength training [18, 19, 21, 22].

One limitation to this study should be noted. There were no physiological fitness measures included in the study even though a periodized strength training was implemented. Changes in strength, power of lower and upper limbs as isometric strength and endurance of core muscles could have been included. It is highly recommended to do a follow up study to examine those physiological variables.

\section{Conclusions}

The study showed that there is a need for injury prevention program for students of University of Sport and Physical Education in Gdansk. Almost half of 82 volunteered students to the study were at higher risk to sustain a musculoskeletal injury due to cut off total score $\leq 14$ on the FMS test.

According to the results of the research, FST is an effective method in improving low FMS total scores in young adults that are at higher risk to sustain a musculoskeletal injury. Future studies should examine the injury rate among students of physical education at sport universities and compare more modes of training in improving FMS scores.

\section{Conflict of interest}

The author declares that there is no conflict of interest.

\section{References}

1. Hootman JM, Dick R, Agel J. Epidemiology of collegiate injuries for 15 sports: Summary and recommendations for injury prevention initiatives. Journal of Athletic Training, 2007:42:311-9.

2. Cook G, Burton L, Hoogenboom BJ, Voight M. Functional movement screening: the use of fundamental movements as an assessment of function - part 1. International Journal of Sports Physical Therapy, 2014;9(3):396-409.

3. Gribble PA, Hertel J, Plisky P. Using the star excursion balance test to assess dynamic postural-control deficits and outcomes in lower extremity injury: A literature and systematic review. Journal of Athletic Training. National Athletic Trainers Association, 2012;47:339- 57. https://doi.org/10.4085/1062-6050-47.3.08

4. Harris-Hayes M, Van Dillen LR. The Inter-Tester Reliability of Physical Therapists Classifying Low Back Pain Problems Based on the Movement System Impairment Classification System. $P M \& R, 2009 ; 1: 117-26$. https://doi.org/10.1016/j.pmrj.2008.08.001

5. Kritz M, Cronin J, Hume P. The bodyweight squat: A movement screen for the squat pattern. Strength and Conditioning Journal, 2009;31(1):76-85. https://doi.org/10.1519/SSC.0b013e318195eb2f

6. Bonazza NA, Smuin D, Onks CA, Silvis ML, Dhawan A. Reliability, Validity, and Injury Predictive Value of the Functional Movement Screen. American Journal of Sports Medicine, 2017;45(3):725-32. https://doi.org/10.1177/0363546516641937

7. Bunn Pdos S, Rodrigues AI, Bezerra da SilvaE. The association between the functional movement screen outcome and the incidence ofmusculoskeletal injuries:Asystematic review with meta-analysis. Physical Therapy in Sport, 2019;35:146-58. https://doi.org/10.1016/j.ptsp.2018.11.011

8. MooreE,Chalmers S, MilaneseS,FullerJT.Factors Influencing the Relationship Between the Functional Movement Screen and Injury Risk in Sporting Populations: A Systematic Review and Meta-analysis. Sports Medicine, 2019;49(9):1449-63. https://doi.org/10.1007/s40279-019-01126-5

9. Cook G, Burton L, Hoogenboom BJ, Voight M. Functional movement screening: the use of fundamental movements as an assessment of function-part 2. International Journal of Sports Physical Therapy, 2014;9(4):549-63.

10.Kiesel, KB, Plisky, Kersey P. Function movement test score as a predicator of time-loss during professional football team's preseason. Medicine
\& Science in Sport \& Exercise, 2008;40: 234. https://doi.org/10.1249/01.mss.0000322505.56453.84

11. Stanek JM, Dodd DJ, Kelly AR, Wolfe AM, Swenson RA. Active duty firefighters can improve Functional Movement Screen (FMS) scores following an 8-week individualized client workout program. Work, 2017;56(2):213-20. https://doi.org/10.3233/WOR-172493

12.Baron J, Bieniec A, Swinarew AS, Gabryś T, Stanula A. Effect of 12-week functional training intervention on the speed of young footballers. International Journal Environmental Researh and Public Health, 2020;17(1):160-70. https://doi.org/10.3390/ijerph17010160

13.Rey E, Padrón-Cabo A, Penedo-Jamardo E, GonzálezVillora S. Effect of the 11+ injury prevention programme on fundamental movement patterns in soccer players. Biology of Sport, 2018;35(3):229-36. https://doi.org/10.5114/biolsport.2018.74636

14.Lago-Fuentes C, Rey E, Padrón-Cabo A, De Rellán-Guerra AS, Fragueiro-Rodríguez A, García-Núñez J. Effects of core strength training using stable and unstable surfaces on physical fitness and functional performance in professional female futsal players. Journal of Human Kinetics, 2018;65(1):213-24. https://doi.org/10.2478/hukin-2018-0029

15.Bodden JG, Needham R. The effect of an intervention program on FMS test scores in MMA athletes. Journal of Strength and Conditioning Research, 2015;29(1):219-25. https://doi.org/10.1519/JSC.0b013e3182a480bf

16.Jafari M, Zolaktaf V GG. Functional Movement Screen (FMS) Composite Scores in Firefighters: Effects of Corrective Exercise Training. Journal of Sports Rehabilitation, 2018;29(1):102-106. https://doi.org/10.1123/jsr.2018-0080

17.St. Laurent CW, Masteller B, Sirard J. Effect of a suspension-trainer-based movement program on measures of fitness and functional movement in children: A pilot study. Pediatric Exercise Science, 2018;30(3):364-75. https://doi.org/10.1123/pes.2016-0278

18. Yildiz S, Pinar S, Gelen E. Effects of 8-week functional vs.traditional training on athletic performance and functional movement on prepubertal tennis players. Journal of Strength and Conditioning Research, 2019;33(3):651-61. https://doi.org/10.1519/JSC.0000000000002956

19.Liao T, Li L, Wang YT. Effects of functional strength training program on movement quality and fitness performance among girls aged 12-13 years. Vol. 33, Journal of Strength and Conditioning Research, 2019;33(6): 1534-41. 
https://doi.org/10.1519/JSC.0000000000002190

20.Cosio-Lima L, Knapik JJ, Shumway R, Reynolds K, Lee Y, Greska E, Hampton M. Associations Between Functional Movement Screening, the Y Balance Test, and Injuries in Coast Guard Training. Military Medicine, 2016;181(7):643--8. https://doi.org/10.7205/MILMED-D-15-00208

21.Tomljanović M, Spasić M, Gabrilo G, Uljević O, Foretić N. Effects of five weeks of functional vs. traditional resistance training on anthropometric and motor performance variables. Kinesiology, 2011;43(2):145-54.

22. Weiss T, Kreitinger J, Wilde H, Wiora C, Steege M, Dalleck L, Jannot J. Effect of Functional Resistance Training on Muscular Fitness Outcomes in Young Adults. Journal of Exercise Science and Fitness, 2010;8(2):113-22. https://doi.org/10.1016/S1728-869X(10)60017-2

23.Matveev LP. Fundamentals of Sports Training. Moscow: Progress Publishers; 1981.

24.Helms ER, Cronin J, Storey A, Zourdos MC. Application of the Repetitions in Reserve-Based Rating of Perceived Exertion Scale for Resistance Training. Strength and Conditioning Journal, 2016;38(4):42-9. https://doi.org/10.1519/SSC.0000000000000218

25.Willigenburg N, Hewett TE. Performance on the functional movement screen is related to hop performance but not to hip and knee strength in collegiate football players. Clinical Journal of Sport Medicine, 2017;27(2):119-26. https://doi.org/10.1097/JSM.0000000000000317

26.Cook G, Burton L, Fields K, Danville KK editors. The Functional Movement Screen; Athletic Testing Services;2012.

27.Nadler SF, Moley P, Malanga GA, Rubbani M, Prybicien M, Feinberg JH. Functional deficits in athletes with a history of low back pain: A pilot study. Archives of Physical Medicine and Rehabilitation, 2002;83(12):1753-8. https://doi.org/10.1053/apmr.2002.35659

28.Bigos SJ, Batti'E MC, Fisher LD, Hansson TH, Jones ME, Wortley MD. Isometric lifting strength as a predictor of industrial back pain reports. Spine, 1989;14(8):851-6. https://doi.org/10.1097/00007632-198908000-00014

29.Williams TD, Tolusso DV, Fedewa MV, Esco MR. Comparison of Periodized and Non-Periodized Resistance Training on Maximal Strength: A MetaAnalysis. Sports Medicine, 2017;47:2083-100. https://doi.org/10.1007/s40279-017-0734-y

30.Cosio-Lima LM, Crawley A, Adlof LE, Straughn M, Wallop JD, Lee Y. Effects of a Periodized Training Program and a Traditional Military Training Program on Functional Movement and Y-Balance Tests in ROTC Cadets. Sports and Exercise Medicine Open Journal, 2017;3(2):46-52.

\section{Information about the author:}

Michał Sawczyn; http://orcid.org/0000-0002-0077-3965; michal.sawczyn@awf.gda.pl; Gdansk University of Physical Education and Sport; Gdańsk, Poland.

\section{Cite this article as:}

Michał Sawczyn. Effects of a periodized functional strength training program (FST) on Functional Movement Screen (FMS) in physical education students. Physical Education of Students, 2020;24(3):162-167. https://doi.org/10.15561/20755279.2020.0306

This is an Open Access article distributed under the terms of the Creative Commons Attribution License, which permits unrestricted use, distribution, and reproduction in any medium, provided the original work is properly cited http://creativecommons.org/licenses/by/4.0/deed.en

Received: 02.04.2020

Accepted: 11.05.2020; Published: 30.06 .2020 